\title{
Blogging as a tool: innovative approaches to information access
}

\section{Jay Bhatt}

Hagerty Library, Drexel University

http://englibrary. blogspot.com http://www. digitaldivide. net/blog/jaybhatt http://www.lisnews.com/ / ay/journal/ 


\section{What is a Blog?}

- Consists of dated entries in reverse chronological order

- Most recent post appears first

- Frequently updated

- Library blog can include news items, announcements, instructional tips, new electronic resources, etc. 


\section{What is RSS?}

- RSS - Real Simple Syndication

It brings contents to you

- Content available as new feeds

- XML based (eXtensible Markup Language) for content distribution called feeds

- Aggregators - contains compilation of feeds

- Collect feeds and display them in easy to read format

- More later during the talk 


\section{What is RSS?}

- Feedreaders (RSS feed readers)

- RSS aggregator or News Reader - a software that enables you to get the latest news headlines in RSS

- $\quad$ delivered straight to your desktop

- Several Feedreaders are available for download at RSS Compendium - RSS readers

.

- Many weblogs have built in RSS feeds.

- RSS feeds are identified by 'XML' or 'RSS' icons

- Just add the URL associated with the icons into your feedreader or bloglines 


\section{Create Blog}

- Blogger is one of the tools to create blogs

- Create your account

- Name your blog

- Choose a template

- Create your blog

- Periodically add items to keep your blog active 


\section{Create Blog}

- Blog: Engineering Resources created

- Under Blogger's Sitefeed provides the URL for the feed

- Feed URL:

http://englibrary.blogspot.com/atom.xml 


\section{Add post in Blog}

Slogger: Engineering Resources : : Manage Posts - Microsoft Internet Explorer

File Edit View Favorites Tools Hep

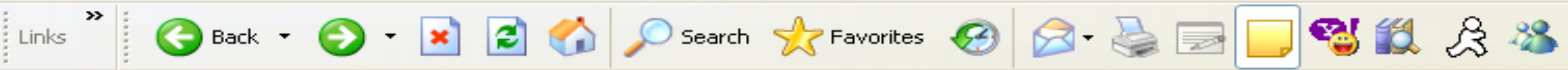

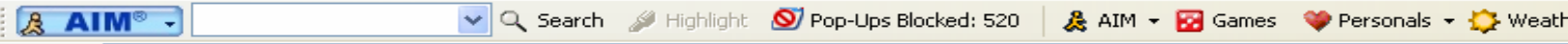
Address hattp://wwww. blogger.com/posts.g?blogID=10922780

\section{E Engineering Resources}

Posting Settings Template View Blog

create Edit posts | status

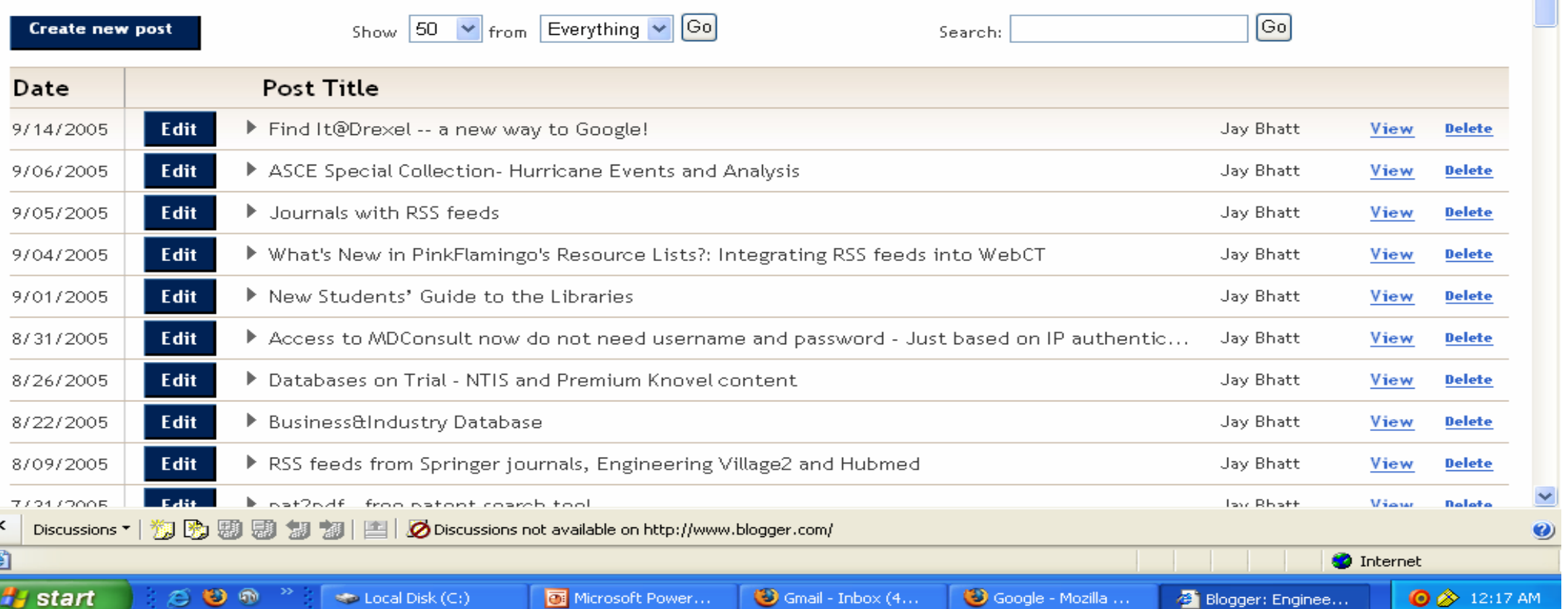




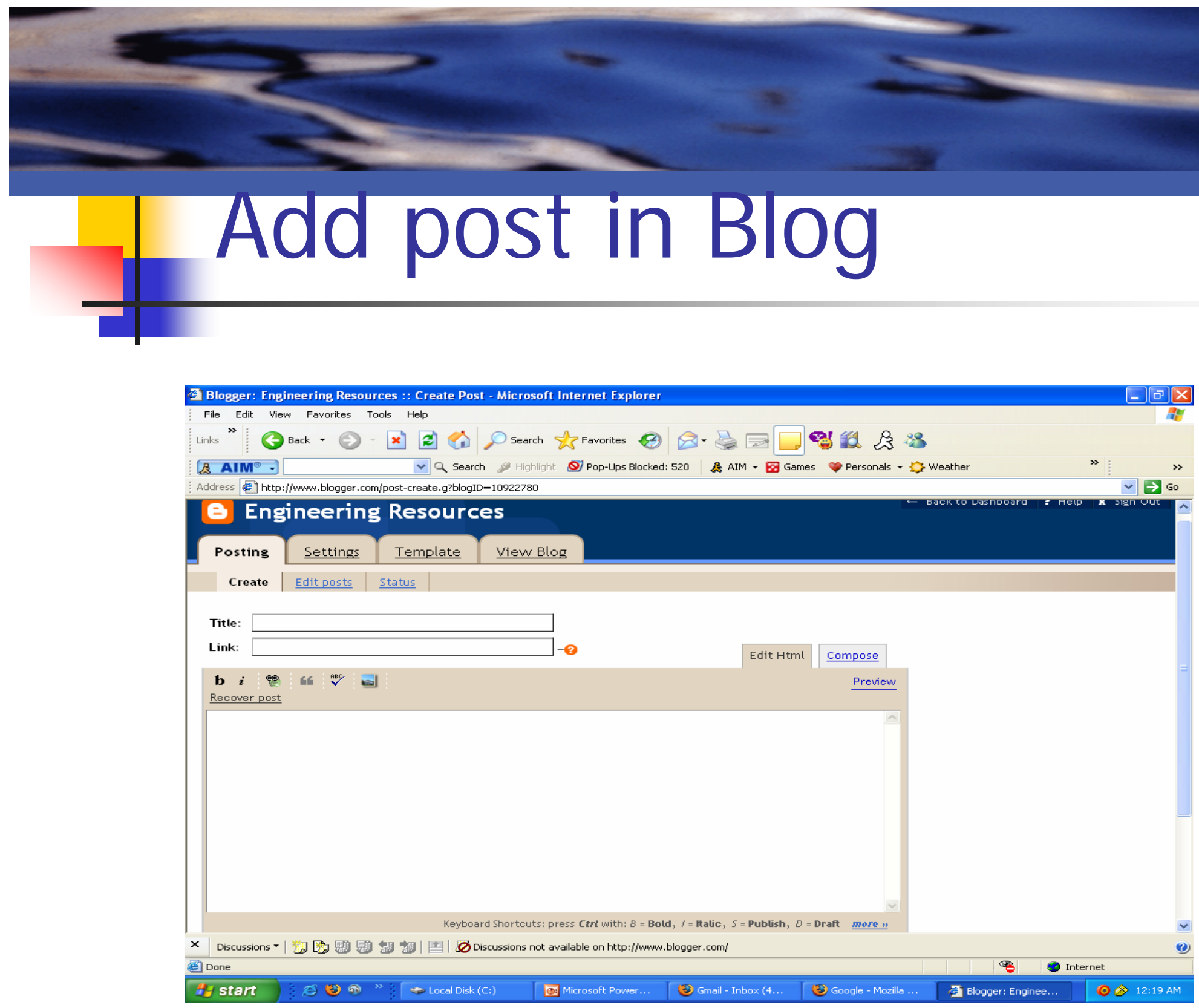




\section{Bloglines}

- Bloglines http://www. bloglines.com

Aggregator online information sources. Free, create account first, no need to download a software

- Subscribe to different RSS feeds from blogs

- News, search queries in databases (Ei Compendex, Proquest, HubMed, etc.)

- Table of contents of journal articles

- To find feeds, look for 'XML' or 'RSS' icon

- Add 'URL' into Bloglines

- Bloglines will constantly check those feeds for changes or additions and direct new information onto your Bloglines personal page.

- Lay's public feeds

- The New York Times RSS feeds 


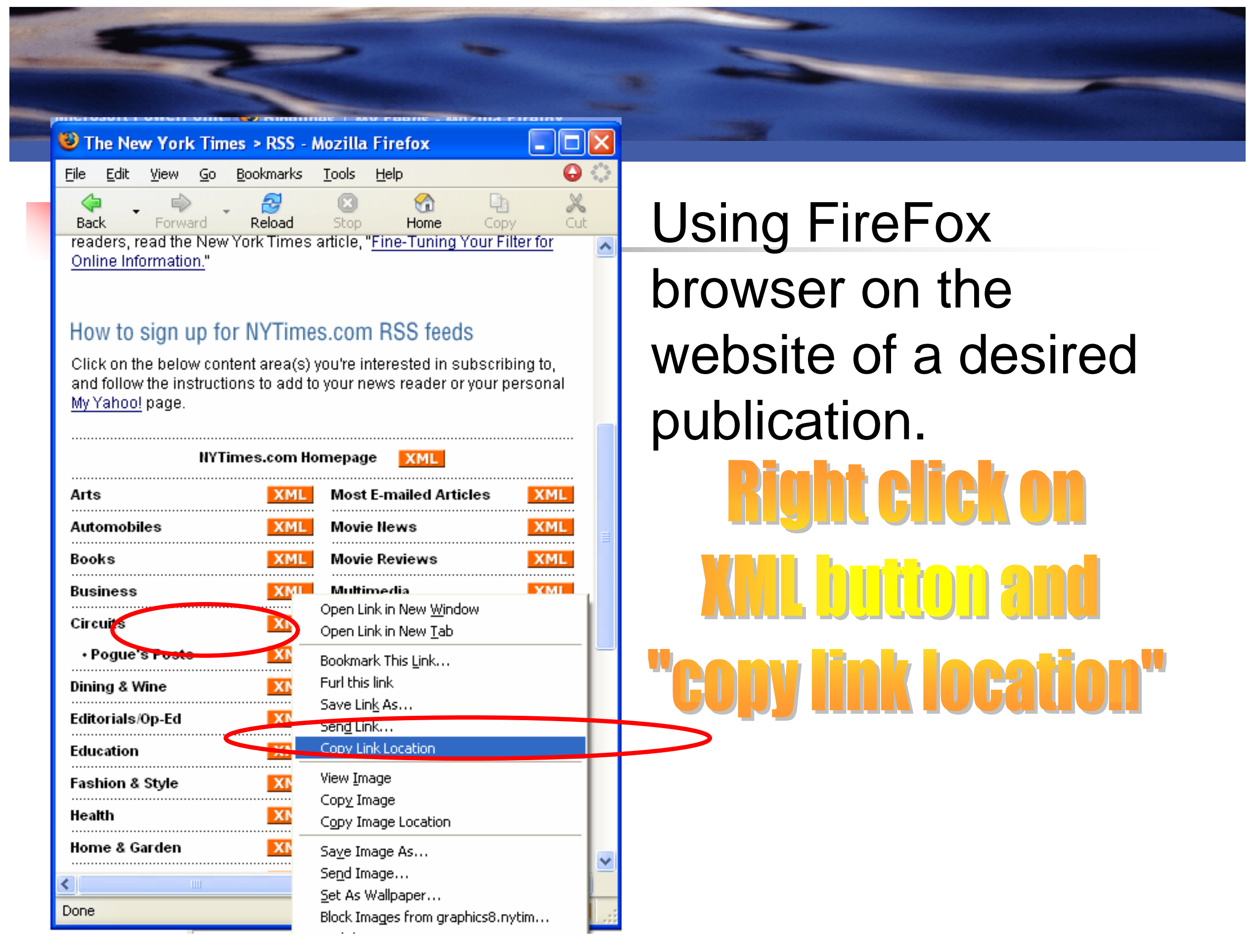



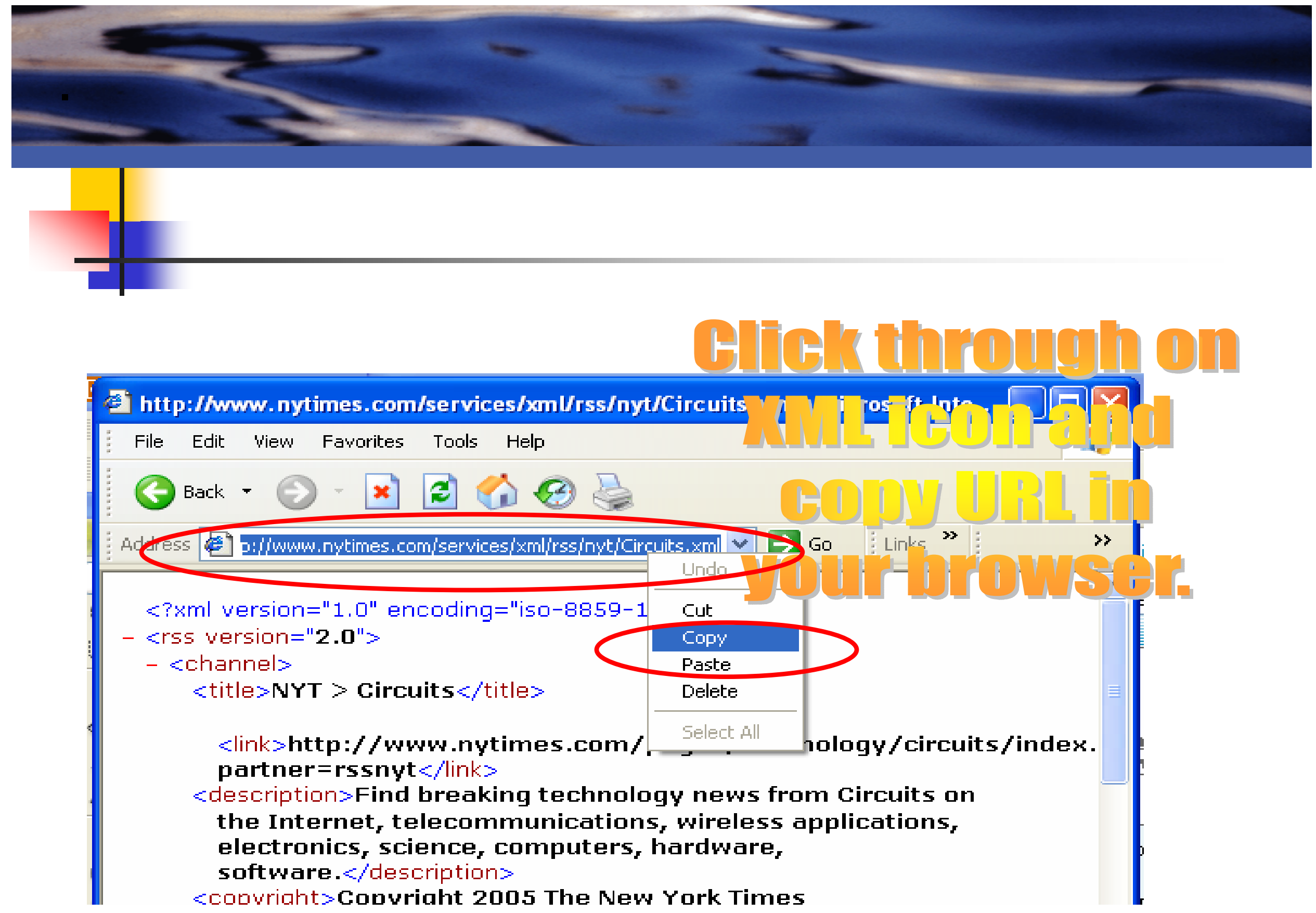

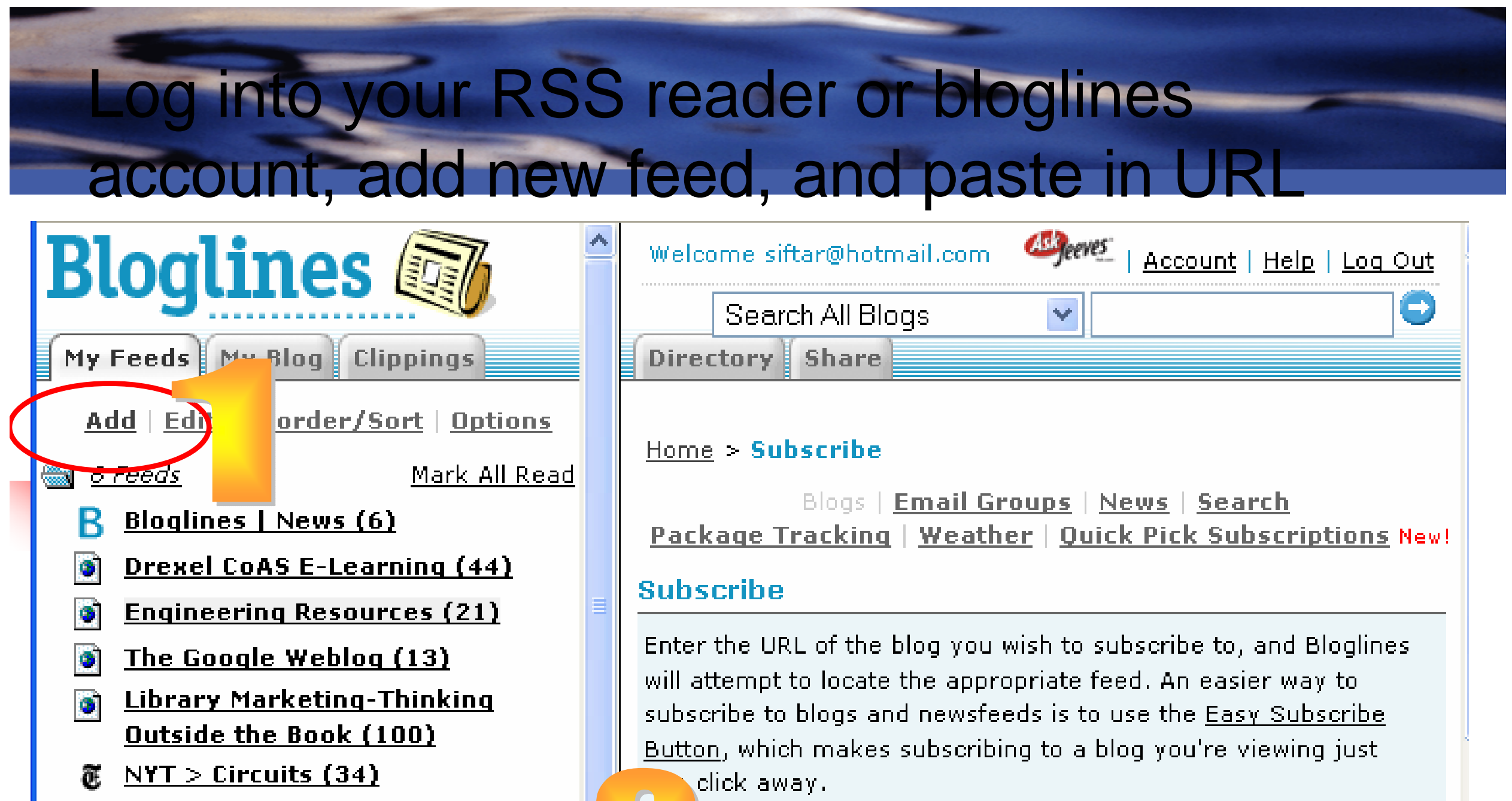

\section{Extras}

\section{$\underline{\text { Recommendations | Tips }}$}

B Create Email Subscriptions

B Open Notifier I Download Notifier

B Get a Subscribe To Bloglines Button

\section{스}

Welcome siftar@hotmail.com ashoever | Account | Help | Log Out
Search All Blogs $\quad \checkmark$

Home $>$ Subscribe

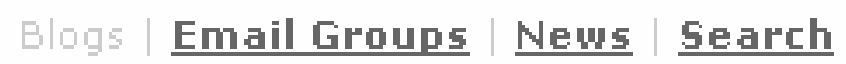

Package Tracking $\mid$ Weather $\mid$ Ouick Pick Subscriptions New!

Subscribe

Enter the URL of the blog you wish to subscribe to, and Bloglines will attempt to locate the appropriate feed. An easier way to subscribe to blogs and newsfeeds is to use the Easy Subscribe Button, which makes subscribing to a blog you're viewing just click away.

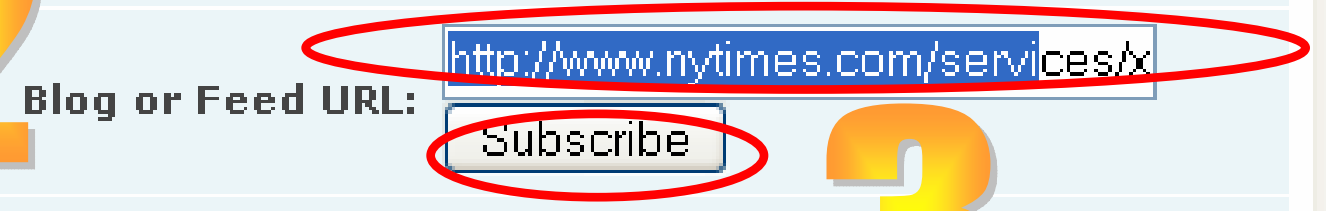

If you know of a blog hosted on Blog Spot, Li... hal, or Xangas, you can simply enter the blog name the blog host and click Subscribe. 


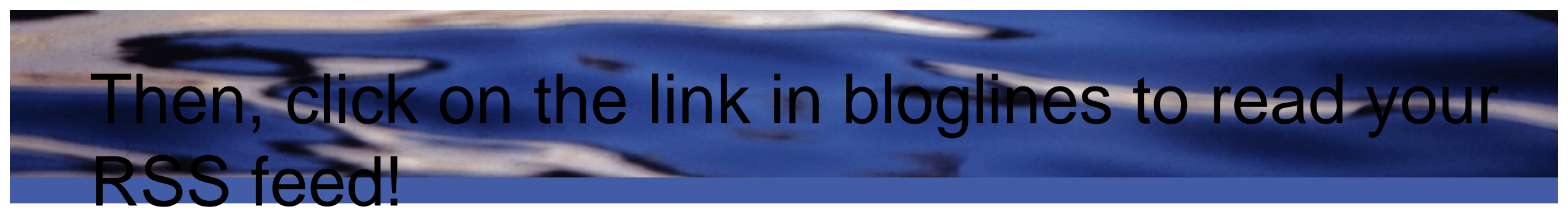

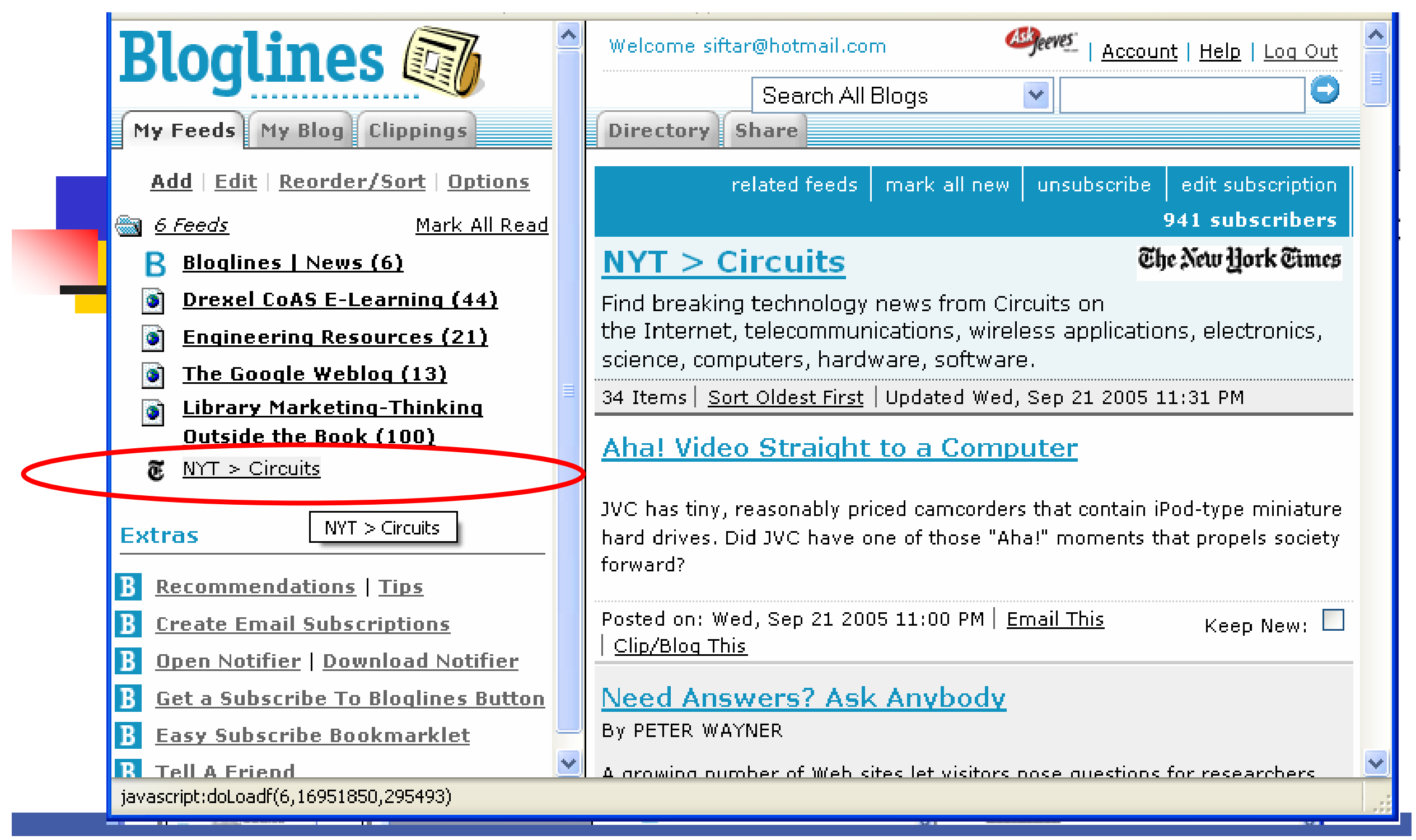




\section{Engineering Resources Blog}

- Engineering Resources Blog

- http://englibrary.blogspot.com

- Announcement of new resources, instructional tips for using a particular database or a resource, new and important web resources and more.

- Archive of information added over a period of time

- Emphasis on resources for CoE and Biomed Eng - mainly subscription based 


\section{Engineering Resources Blog}

- Announcing new books by selected top research keywords:

- New Books in 2005 for some subject areas

- I mportant subject areas

- Availability of both print and electronic books

- Increases visibility of Library books

- May increase usage 


\section{Engineering Resources Blog}

- Announcing the availability of RSS feeds of electronic databases:

- Engineering Village2 RSS feed

- Engineering Village2 - Ei Compendex/I NSPEC

- Search - copy and paste URL into Bloglines under 'Add' in'My Feeds' - URL found by clicking on RSS

- Create appropriate folders to receive feeds in particular

- subject areas

- Excellent way to keep up-to-date with new research

- No need to receive email alerts 


\section{Engineering Resources Blog}

- Announcing the availability of RSS feeds of electronic databases:

- RSS Feeds including HubMed (pubmed rewired)

- HubMed is an alternative interface to the PubMed medical literature

- RSS feeds from Proquest databases

- RSS feeds are available based on Proquest's predetermined search queries

- 'Curriculum Match Factor: RSS Feeds' - Categories 


\section{Engineering Resources Blog}

- Integrating feeds from journals and journal articles

Nature, Nature Biotechnology, Nature Materials - All Nature title feeds

- Institute of Physics

- Science Online RSS feeds

- IngentaConnect

- International J ournal of Applied Ceramic Technology

- Lournal of Failure Analysis \& Prevention

$\square$ 


\section{Engineering Resources Blog}

- IEEE Computer Society

- Royal Society of Chemistry

- Lab on a Chip, Annual Reports A: Inorganic Chemistry and Annual Reports B: Organic Chemistry

- University of Chicago Press Journals

- Biomedical and health sciences electronic journals with available RSS Feeds

- Many more to come including ScienceDirect 


\section{Engineering Resources Blog}

- Instructional Tips - using webCT

- tips on linking journal articles

- Course based tips to find research information

- Bionanotechnology BMES460/BMES480 and Body Synthetic BMES212

Library sessions on blogging in both classes integrated with research seminar 


\section{Engineering Resources Blog}

- Announcing library events on the blog

- Scholarly Communication Speaker Series

- RefWorks I ntroduction and Training

- Library tours and orientations

- Open House 


\section{created blogs}

- Faculty blogs

- I dentify faculty working on blogs

- Drexel CoAS E-Learning blog

- Civil, Architectural and Envi. Eng

- Drexel E-Learning Podcasts

- One more opportunity to work together 


\section{Vision}

- More and more electronic journals will have RSS feeds

- Databases - IEEE is working on it

- ScienceDirect

- Possibly Google Scholar soon

- Refworks - group members receive RSS feeds of the citations added (future?)

- Active collaboration with faculty and students essential

- More outreach necessary 


\section{Thank You!}

- Thanks very much and have fun creating blogs

- Please send me your feedback

- Interested in creating and developing a collaborative blog?

- Contact me anytime at bhattji@drexel.edu 